\title{
Evaluation of Fracture Toughness and Crack Propagation of Aluminum Alloy 7075-T651 with Chromium Oxide Coating
}

\author{
E. Altuncu ${ }^{a, *}$ And S. $\operatorname{IRIC}^{b}$ \\ ${ }^{a}$ Sakarya Applied Sciences University, Tech. Fac., Metallurgy and Materials Eng. Dept., 54187 Turkey \\ ${ }^{b}$ Sakarya Applied Sciences University, Eng. Fac., Mechanical Eng. Dept., 54187 Turkey \\ Fatigue crack formation is the most important factor affecting the damage in parts under subjected to the \\ repeated stresses. In this context, intensive researches are continuing on the protective hard coatings in the aviation \\ and automotive sectors in order to increase the fatigue life especially in aluminum alloy parts. Chromium oxide \\ $\left(\mathrm{Cr}_{2} \mathrm{O}_{3}\right)$ based coatings are widely used in many industrial applications due to high corrosion resistance, high \\ hardness and high surface resistance. In this study, fatigue crack propagation on 7075-T651 alloy with chromium \\ oxide coating by thermal spraying method was investigated. Test results show that the crack propagation is slowed \\ down by the chromium oxide based coating and increase the surface resistance of the aluminum alloy.
}

DOI: 10.12693/APhysPolA.135.877

PACS/topics: thermal spray, chromium oxide, crack propagation, aluminum alloy

\section{Introduction}

The 7075 series aluminum-zinc alloy is a material that attracts great attention in the automotive and aerospace industries. Compared to other aluminum alloy series, it has higher specific strength but also has an average fatigue and corrosion resistance. The mechanical properties of 7075 alloy depends on the tempering conditions. T651 tempered 7075 alloy has tensile strength between 500 and $550 \mathrm{MPa}$ and elongation of 5-8\%. 7075-T651 alloy is widely used to make a wide range of aircraft parts. Investigating and improving the fatigue crack behaviour of 7075 aluminium alloy is so important. The fatigue crack behaviour is significantly affected by the surface defects and residual stress in material. Tensile stress in the surface can promote the generation and propagation of fatigue cracks. It is necessary to increase the surface stresses or to increase the surface resistance in order to reduce the fatigue crack in the parts working under repeated stress conditions. Surface resistance enhancement methods and hard coating technologies have been researched for improving the fatigue lifespan of alloys [1-7]. Among these technologies, shot peening is widely applied. But it is anticipated to be a more effective coating solution to increase both fatigue life and to increase corrosion resistance. Hard and dense oxide-based coatings produced by thermal spray technique can be used to overcome this engineering problem. The high velocity oxy fuel (HVOF) spray process is a thermal spray method that allows the powder particles to be sprayed onto the surface at very high speeds, which is fed to the high-energy flame jet resulting from the combustion of the oxygen and fuel mixture. As a result, a very dense and hard coatings can be obtained. Carbide-based coat-

*corresponding author; e-mail: altuncu@subu.edu.tr ings produced by the HVOF spray process are generally preferred for fatigue and wear resistance enhancement studies. It is necessary to avoid overheating during coating with HVOF process on aluminum alloys. The flexicord flame spray process, which consists of ceramic particles in a polymeric sheath, is an economical alternative to the HVOF and plasma spray processes. Until today, there are many studies on tungsten carbide (WC) and chromium carbide $\left(\mathrm{Cr}_{2} \mathrm{C}_{3}\right)$ based coatings [4]. Up to now there is not enough scientific study on oxide based flexicord flame spray coatings. Chromium oxide $\left(\mathrm{Cr}_{2} \mathrm{O}_{3}\right)$ based coatings are preferred in industrial applications due to both high corrosion resistance and high hardness [5]. With flexicord flame spray process, hard ceramic coatings without porosity can be produced. In this study, fatigue resistance and crack growth on chromium oxide coated 7075-T6 alloy was investigated according to ASTM E399.

\section{Experimental details}

The material investigated was 7075 aluminum alloy with a chemical composition of $5.6 \mathrm{Zn}, 1.8 \mathrm{Cu}, 2.4 \mathrm{Mg}$, $0.22 \mathrm{Cr}$ [wt\%]. The samples subjected to T651 heat treatment had a tensile strength and elongation of $536 \mathrm{MPa}$, and $7.6 \%$, respectively. All samples were fabricated according to ASTM E399 [7]. According to the standard testing procedures the coated samples are tested under mode-I fracture in TL orientation ( $(\mathrm{L})$ longitudinal, $(\mathrm{T})$ transverse). All samples were pre-cracked at $5 \mathrm{~Hz}$, with load ratio of $0.1(\mathrm{R})$. In the experimental studies, the plane stress fracture toughness $K_{I C}$ was investigated using fatigue pre-cracked specimens. Fracture toughness measurement on compact test (CT) specimens have been carried out on MTS 810 machine with a load cell of $100 \mathrm{kN}$. Before coating, to improve the surface roughness and coating adhesion, substrates were subjected to grit blasting utilizing alumina (Grit 80). NiCr based (80wt\%-20 wt\%) bond coat is applied to the interface 
before spraying the ceramic layer. Test samples were coated with $\mathrm{Cr}_{2} \mathrm{O}_{3}$ (purity 99.2 wt\%) based ceramic. Feedstock materials is a ceramic powder filled flexy polymer cord and flexicord diameter: $4.7 \mathrm{~mm}$, powder particle size: $35 \pm 8 \mu \mathrm{m}$. During the spraying, the polymeric sheath is evaporated away and allows for the production of a homogeneous coating structure. During spraying the layer thickness of approximately $15 \pm 3 \mu \mathrm{m}$ per pass. During spraying, Master Jet ${ }^{\circledR}$ (Saint Gobain) flexicord spray gun was used. Spray parameters: gas/fuel pressure: $\mathrm{O}_{2} / \mathrm{C}_{2} \mathrm{H}_{2}: 4 / 1.2$ bar, feed rate: $50 \mathrm{~cm} / \mathrm{min}$, spray distance: $80 \mathrm{~mm}$. Coatings in two different thicknesses were produced. OM and SEM analysis were carried out on coated substrates to observe the microstructure, coating defects like micro cracks and pores, uniform distribution of coated powder particles and coating thickness of developed coatings. Vickers hardness tester was used to determine the micro hardness of coated substrates. For all the tests, $100 \mathrm{~g}$ load for $10 \mathrm{~s}$ was adopted. The test was performed at 3 different locations of the coatings. The adhesion test of the coatings was carried out according to ASTMC633 standard. Sample discs were placed between two rods with FM1000 Adhesive Film between the opposing surfaces. The test jigs were placed in an oven for $2 \mathrm{~h}$ at $190^{\circ} \mathrm{C}$.

\section{Results and discussions}

Figure 1 shows SEM (scanning electron microscope) images of thermal sprayed $\mathrm{Cr}_{2} \mathrm{O}_{3}$ coating microstructures. Good bonding between the ceramic coating layer and aluminum alloy substrate. After the metallographic preparation, a very low porosity was found in the microstructure investigations in the coating section. Due to the nature of the coating process, micron scale porosity and micro cracks can be observed in the coating structure. These helps the coating to get elasticty in workpieces running under repeated stresses. Top coating thicknesses are measured $45 \pm 10 \mu \mathrm{m}$ and $85 \pm 15 \mu \mathrm{m}$ respectively. Bond coating thickness is $15 \pm 5 \mu \mathrm{m}$. Surface roughness ( $\mathrm{Ra}$ ) of coatings is $3 \pm 0.2 \mu \mathrm{m} . \mathrm{Cr}_{2} \mathrm{O}_{3}$ coated samples posses microhardness of $950-1060 \pm 40 \mathrm{HV}_{0.1}$ and uncoated sample of $200 \pm 15 \mathrm{HV}_{0.1}$. The porosity ratio in the coatings is less than $1 \%$ (measured by IA). The fractographic analysis of the fractured surface provides important verify on the failure mechanism. The fracture surfaces are detaily examined under SEM.

Figure 2 shows the coated specimens and fracture surface after the fatigue test. The fracture surface consists of two zones. Uncoated 7075-T651 specimen showed a stable and unstable crack growth zones. In fatigue fracture studies, stabilized and non-stabilized surfaces at the fracture surface give an idea of the crack propagation rate. Stable zone is relatively flat, smooth and not show any deep dimples. However unstable zone shows rough and show deep dimples and micron sized crack paths and craters. Coated samples showed only unstable crack growth region due to the strong bonding between the alloy and coating [8].

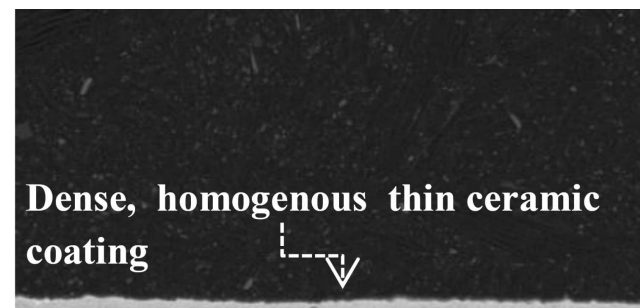

\section{Substrate: 7075-T651 alloy}

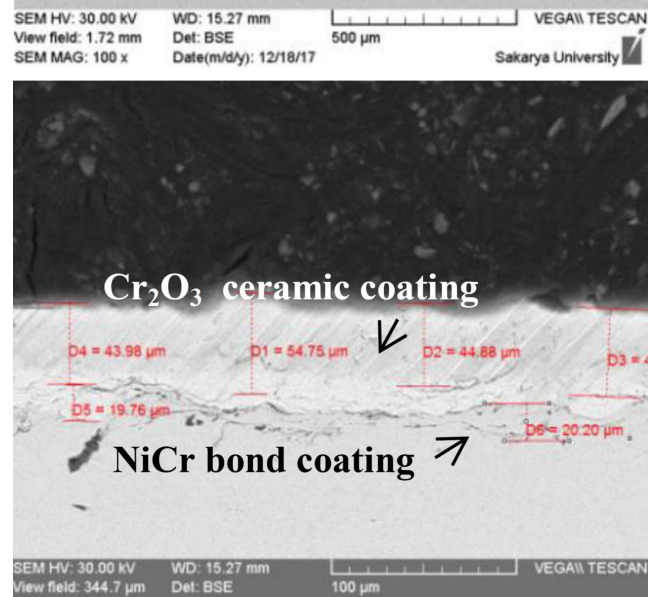

Fig. 1. SEM images cross section of chromium oxide coating.
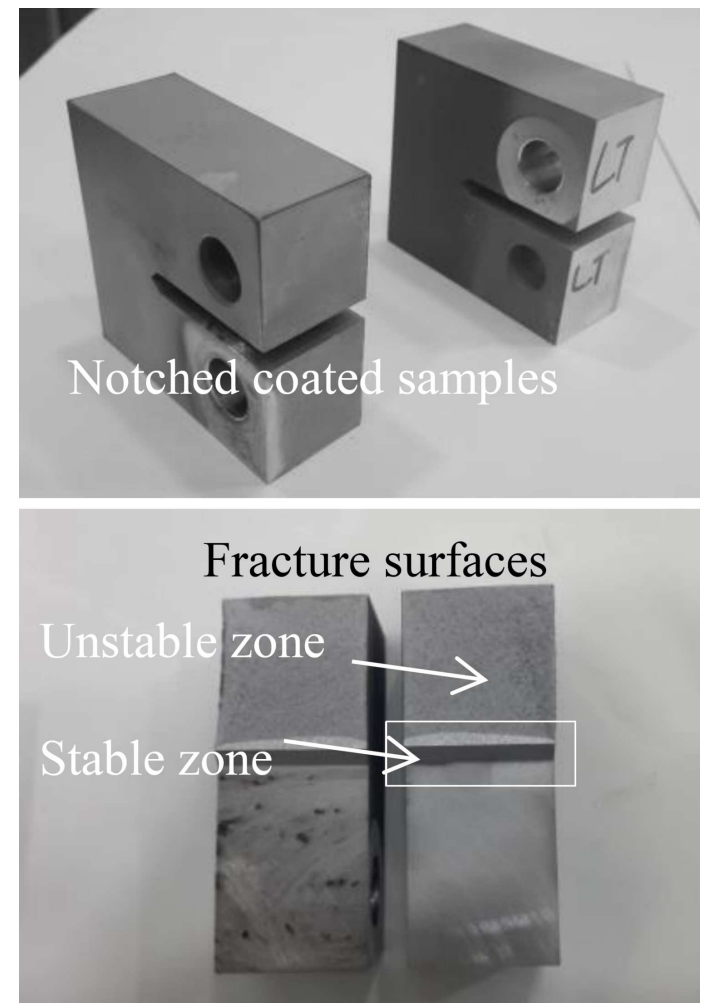

Fig. 2. Chromium oxide coated test samples (top) and fracture surface (bottom). 

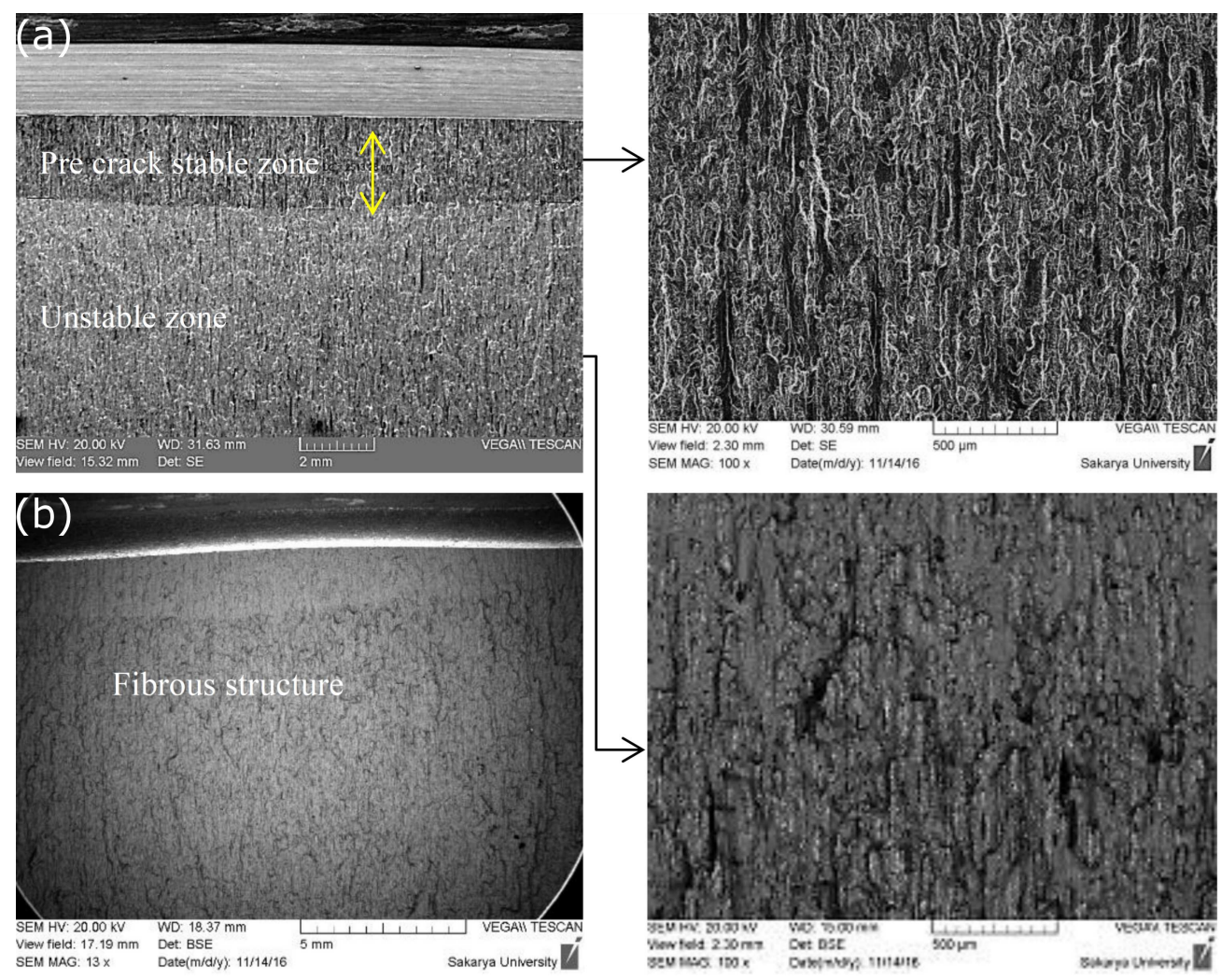

Fig. 3. SEM images of fracture surfaces of the samples: (a) uncoated sample and details, (b) fibrous structure of coated sample.

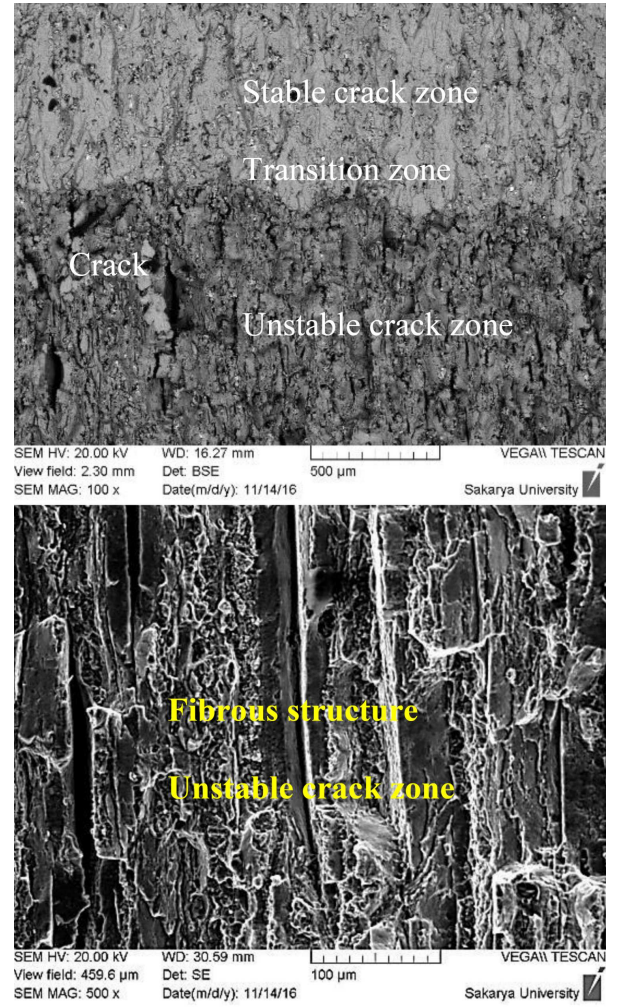

Fig. 4. SEM images of fracture surfaces for coated samples at higher magnifications.
The stable fracture surface zone is in an elliptical form, ranging from about $2.2 \mathrm{~mm}$ to $2.4 \mathrm{~mm}$ in width. The nonstable fracture zone exhibits a fibrous and coarse fracture surface (Fig. 3a). In Fig. 3b, the fibrous structure can be clearly seen in an electron microscope image taken at high magnifications. The ceramic coating prevent and delays the crack propagation. As the coating thickness increases, the zone of the stabile crack region becomes narrower. In coated specimens this zone width varies from 1.7 to $1.9 \mathrm{~mm}$.

Figure 4 shows the fracture surface morphology. Stable and unstable fracture traces and transitional area are clearly visible in the fracture site. especially in high magnifications, a fibrous structure emerges.

TABLE I

Fracture toughness measurement and test values. Transverse orientation, U - uncoated 7075-T651 substrate, $\mathrm{L}$ - low thickness $(45 \mu \mathrm{m}) \mathrm{Cr}_{2} \mathrm{O}_{3}$ coated substrate, $\mathrm{H}$ - high thickness $(85 \mu \mathrm{m}) \mathrm{Cr}_{2} \mathrm{O}_{3}$ coated substrate, $w=0.025 \mathrm{~m}$. The test was repeated 3 times and the average value was calculated.

\begin{tabular}{c|c|c|c|c}
\hline \hline Code & $a[\mathrm{~m}]$ & $P[\mathrm{kN}]$ & $K[\mathrm{MPa} / \sqrt{m}]$ & $\Delta K[\%]$ \\
\hline $\mathrm{U}$ & 0.026 & 11.592 & 22.000 & - \\
$\mathrm{L}$ & 0.0276 & 12.05 & 24.64 & +12 \\
$\mathrm{H}$ & 0.0272 & 13.03 & 25.96 & +18
\end{tabular}


When the fracture toughness test results are compared, the coated samples exhibit higher values than the uncoated ones. It was observed that the increase of the coating thickness increased the coating resistance and contributed to the increase of the fracture toughness (Table I).

\section{Conclusion}

Oxide based coatings are preferred to carbide coatings because they have the ability to work at higher temperatures and have higher corrosion resistance. When the aluminium alloy CT specimens are coated with chromium oxide based ceramic, the fracture toughness values are improved when compared with the uncoated. The fatigue crack growth rate for uncoated 7075-T651 alloy specimens are lower than after thermal spray coated samples. The fracture toughness obtained with chromium oxide $\left(\mathrm{Cr}_{2} \mathrm{O}_{3}\right)$ coated specimens are in average $12-18 \%$ higher compared to the uncoated aluminum alloy specimens. Depending on the spray parameters and the chemical composition of the feedstock powder, the coating substrate adhesion properties are controlled. The flexicord spray method developed as an alternative to conventional thermal spray methods provides a high adhesion to the base and demonstrates a homogenous microstructure. The surface resistance of the substrate can be increased by obtaining an dense coating layer with appropriate thicknesses under optimum spraying conditions. In the tests (ASTM C633) carried out on the coated samples, the adhesion test results were obtained at $35 \mathrm{MPa}$ in thin coatings $(45 \mu \mathrm{m})$ and $42 \mathrm{MPa}$ in thick $(85 \mu \mathrm{m})$ coatings. It was observed that the coating was not separated from the base. In the fatigue crack development tests, crack growth rate decreased as a result of the increase in coating thickness. It is clearly shown that the fracture toughness of the coated alloys increases with the increase in the thickness and intersplat adhesion of the coating.
The SEM micrographs of cracked surfaces of the coated specimens showed relatively higher stable crack growth compare to uncoated alloy. Production of homogeneous thickness and low porosity coating plays an effective role in better adhesion of the coating and increasing mechanical properties. With the flexicord flame spray method, it is possible to obtain $1 \%$ porosity and $\mathrm{HV}>900 \mathrm{mi}-$ crohardness in the coatings as a result of the optimum spray parameters. With the application of different ceramic based coatings $\left(\mathrm{Al}_{2} \mathrm{O}_{3} / \mathrm{TiO}_{2}\right.$ etc. $)$, similar tests can be repeated and the effect of fatigue crack development can be better understood.

\section{Acknowledgments}

The authors thank the director of Sakarya University, Thermal Spray Technology R\&D Laboratory and Computational and Experimental Fracture Mechanics (CEFM) Laboratory for supporting this study.

\section{References}

[1] M.N. James, D.J. Hughes, Z. Chen, H. Lombard, D.G. Hattingh, D. Asquith, J.R. Yates P.J. Webster, Eng. Fail. Anal. 14, 384 (2007).

[2] U. Zupanc, J. Grum, J. Mater. Proc. Tech. 210, 1197 (2010)

[3] J.T. Burns, J. Boselli, Int. J. Fatigue 83, 253 (2016).

[4] R.C. Souza, H.J.C. Voorwald, M.O.H. Cioffi, Surf. Coat. Tech. 203, 191 (2008).

[5] A. Cellard, V. Garnier, G. Fantozzi, G. Baret, P. Fort, Ceram. Int. 35, 913 (2009).

[6] S. Mohan Kumar, R. Pramod, M.E. Shashi Kumar, H.K. Govindaraju, Proc. Eng. 97, 178 (2014).

[7] ASTM E399-99(1999), Standard test method for plane-strain fracture toughness of metallic materials, ASTM International, West Conshohocken (PA) 1999.

[8] E. Altuncu, S. Iriç, Acta Phys. Pol. A 132, 926 (2017). 